\title{
Monitoring Suhu udara Kawasan Gunung Aktif berbasis loT
}

\author{
Rachmat Aulia ${ }^{1}$, Abdul Jabbar Lubis ${ }^{2}$, Haris $^{3}$ \\ 1,2,3 Universitas Harapan Medan, Program Studi Teknik Informatika, Medan, Indonesia \\ ํzionisme333@gmail.com \\ Correspondence*
}

\begin{abstract}
ABSTRAK
Tujuan dari Penelitian ini adalah untuk membuat alat monitoring suhu pada gunung - gunung aktif dengan menggunakan sensor LM35 sebagai sensor suhu pada objek yang diteliti, Arduino sebagai pemrosesan data dan memanfaatkan teknologi Internet Of Things (IOT) sebagai sarana informasi secara cepat dan akurat. Metode penelitian yang digunakan dalam penelitian ini adalah metode prototype. Alat ukur ini dibuat menggunakan modul Arduino ESP6288 yang diprogram dengan menggunakan bahasa pemrograman $\mathrm{C}$ dan komputer sebagai antarmuka. Berdasarkan hasil penelitian dapat disimpulkan bahwa alat ukur yang dirancang dapat mengukur suhu pada sistem dapat memberikan informasi suhu pada LCD, Internet Of Things (IOT) secara tepat dan akurat.
\end{abstract}

Kata Kunci: Arduino, ESP 8266, Internet of things, Monitoring Suhu, Sensor LM35

\begin{abstract}
The purpose of this research is to make temperature safety device on active mounts by using LM35 sensor as temperature sensor at object studied, Arduino as data and utilization of Internet Of Things (IOT) technology as information facility quickly and accurately. The research method used in this research is prototype method. This measuring instrument was built using the Arduino ESP6288 module programmed using the $C$ programming language and the computer as the interface. Based on the results of the study can be concluded that measuring instruments designed to measure the temperature on the system can provide temperature information on the $\angle C D$, Internet Of Things (IOT) precisely and accurately.
\end{abstract}

Keywords: Arduino, ESP 8266, Internet Of things, Temperature Monitoring, Sensor LM35

\section{PENDAHULUAN}

Badan Meteorologi Klimatologi dan Geofisika (BMKG) merupakan lembaga yang alah cuaca dan iklim di Indonesia. Lembaga ini mendirikan stasiun meteorologi di berbagai tempat untuk mengamati kondisi lingkungan yang ada di sekitar stasiun tersebut. Parameter yang diambil adalah suhu, kelembaban, kecepatan, arah angin, curah hujan dan intensitas penyinaran matahari. Dalam mempelajari karakteristik musim di stasiun klimatologi diperlukan pencatatan yang aktif dalam waktu yang lama dari berbagai parameter yang

Program Studi Teknik Informatika 
diperlukan. Hal ini tentu saja tidak mungkin dilakukan oleh manusia untuk menganalisa data.Seiring dengan perkembangan komputer maka sistem tersebut memungkinkan untuk dilakukan sistem komputerisasi penyimpanan data klimatologi.

Sistem monitoring suhu sering digunakan untuk pengukuran di daerah-daerah yang sulit untuk dijangkau manusia seperti gunung, gua atau lembah. Selain itu dalam pemantauan cuaca juga digunakan sistem ini, dimana salah satu parameter cuaca adalah suhu udara.Untuk pemantauan cuaca cukup meletakkan suatu alat yang dipantau dari tempat lain. Alat tersebut berupa monitoring suhu udara.

\section{METODOLOGI PENELITIAN 2.1 SENSOR SUHU LM35}

Sensor suhu LM35 adalah komponen elektronika yang memiliki fungsi untuk mengubah besaran suhu menjadi besaran listrik dalam bentuk tegangan [1].
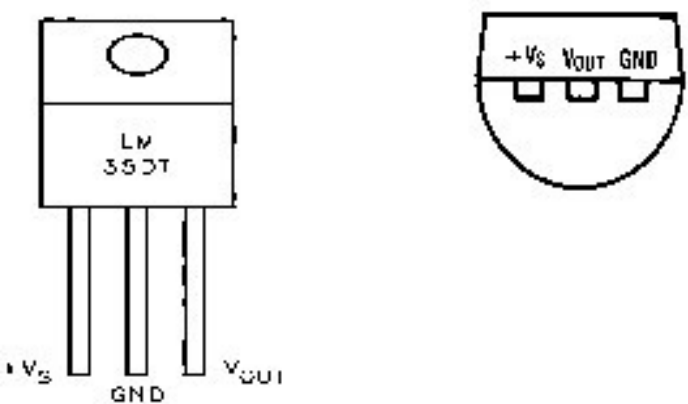

Gambar 1. Sensor Suhu LM35

Sumber: [2]

LM35DZ adalah komponen sensor suhu berukuran kecil seperti transistor (TO-92). Komponen yang sangat mudah digunakan ini mampu mengukur suhu hingga 100 derajat Celcius. [3]

\subsection{Arduino}

Arduino merupakan rangkaian elektronika yang bersifat open source, serta memiliki perangkat keras dan lunak yang mudah untuk digunakan. Arduino dapat mengendalikan lingkungan sekitarnya melalui berbagai jenis sensor dan dapat mengendalikan lampu, motor, dan berbagai jenis aktuator lainnya [4].

Program Studi Teknik Informatika Universitas Prima Indonesia (UNPRI) Medan

\subsection{Arduino ESP 8266}

Arduino ESP 8266 merupakan modul low-cost Wifi dengan dukungan penuh untuk penggunaan $\mathrm{TCP} / \mathrm{IP}$.

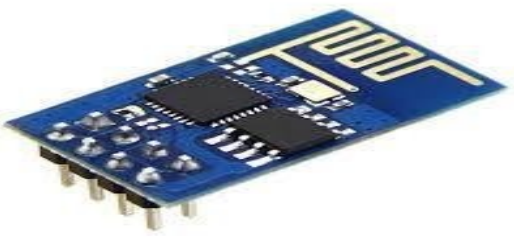

Gambar 2. Arduino ESP 8266

Sumber : [5]

\subsection{IOT (Internet Of Things)}

Internet of Things (IOT) merupakan sebuah konsep yang bertujuan untuk memperluas manfaat dari konektivitas internet yang tersambung secara terus menerus. Suatu benda dikatakan IoT apabila terdapat pada suatu benda elektronik, atau peralatan apa saja yang tersambung ke suatu jaringan local dan global melalui sensor yang tertanam dan selalu aktif.

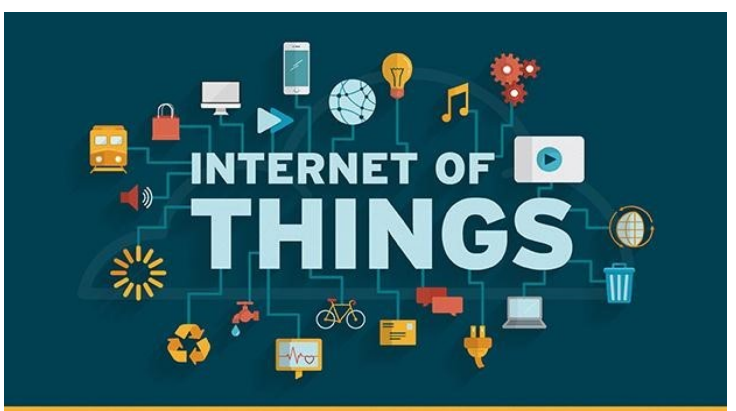

Gambar 3. Internet Of Things

Sumber : [6]

\section{HASIL DAN PEMBAHASAN}

Tujuan dari perangengan ini adalah membuat suatu alat Memonitoring Suhu Udara dengan koneksi internet yang terhubung dengan Internet of Things (IOT). Alat tersebut adalah Arduino ESP8266 sebagai alat Memonitoring yang terhubung ke internet.

\subsection{Diagram Alir Sistem}

Diagram alir sistem adalah gambaran grafis yang memperlihatkan aliran data dari sumbernya dalam 
objek kemudian melewati suatu proses yang mentransformasikan tujuan yang lain. Berikut ini akan dijelaskan beberapa diagram alir sistem yang terdapat pada rangkaian alat ini yaitu sebagai berikut :

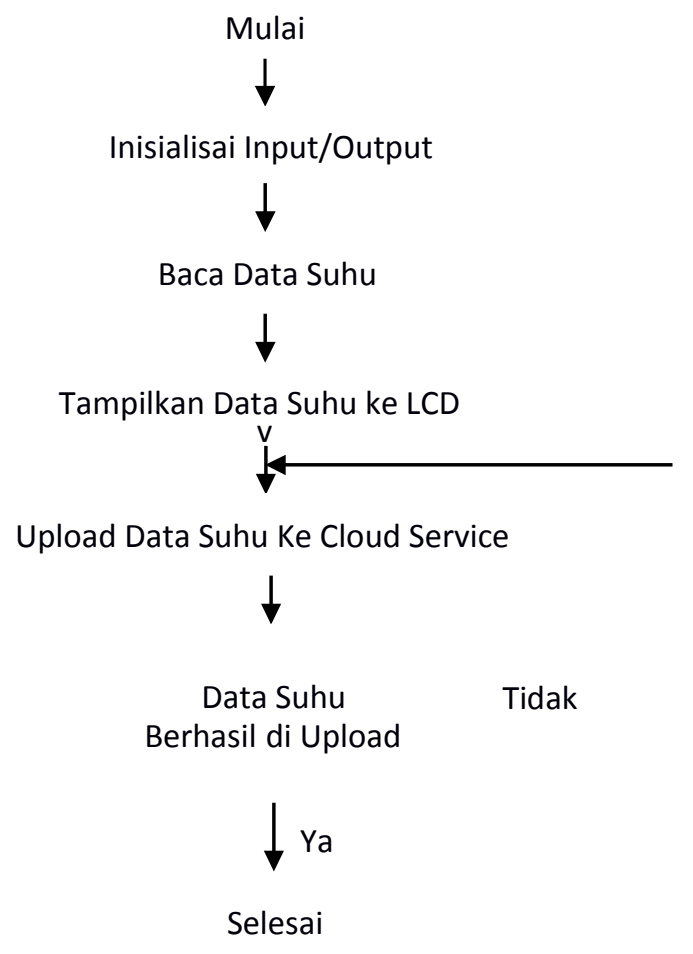

Gambar 4. Flowchart

Diagram diatas adalah diagram alir utam seluruh sistem yang kita rancang yang di awali dengan mulai,setelah itu masuk ke inisialisasi input/ output, setelah itu membaca data suhu kemudian ditampilkan data suhu ke LCD, setelah itu akan di upload data suhu cloud service jika data suhu berhasil di upload maka proses selesai, jika tidak maka kembali ke upload data suhu ke cloud service.

\subsection{Diagram Sensor Suhu LM35}

Diagram alir Sistem adalah gambaran grafis yang memperlihatkan aliran data dari sumbernya dalam objek kemudian melewati suatu proses yang mentransformasikan ke tujuan yang lain. Ada pun diagramnya sebagai berikut :

Mulai

Insialisasi Input/Output

\section{Membaca data dari Sensor Suhu LM35}

digunakan. Berikut adalah penjelasan tentang perancangan rangkaian perangkat keras yang digunkan dalam penelitian ini.

\subsection{Instalasi Rangkaian Arduino ESP826}

Pada penelitian ini penulis menggunakan Arduino ESP8266 sebagai pengendali, Arduino ESP8266 adalah sebuah board mikrokotroller yang berbasis Atmega328 dan sebuah tombol reset. Arduino ini berfungsi sebagai pengola data input dan output semua komponen lainnya, sedangkan rangkaian tombol reset berfungsi sebagai pengulangan kembali arduino apabila tidak berjalan baik ketika dijalankan. Rangkaian arduino ini dapat dilihat pada gambar dibawah ini.

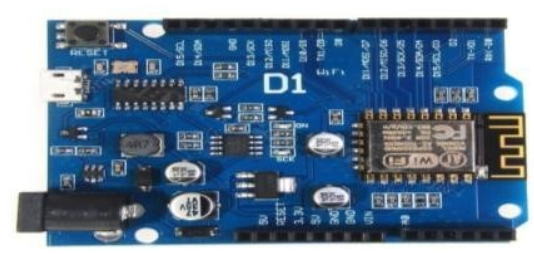

Gambar 6. Rangkaian Arduino ESP8266

Sumber : [7] 


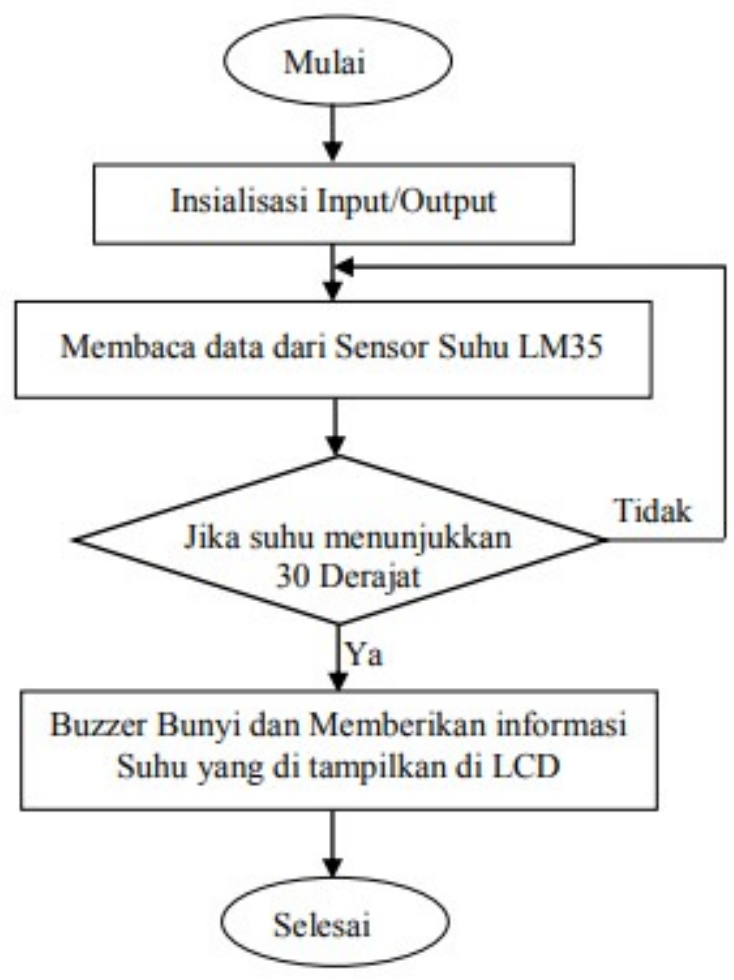

Gambar 5. Flowchart

Diagram diatas adalah diagram alir sistem sensor suhu yang kita rancang yang di awali dengan mulai,setelah itu masuk ke inisialisasi input/output, setelah itu membaca data suhu dari sensor LM35 kemudian ditampilkan data suhu ke LCD, jika suhu menunjukkan 30 derajat celcius maka Buzzer bunyi dan memberikan informasi Suhu yang di tampilkan di LCD, maka proses selesai, jika tidak maka kembali membaca dari sensor suhu LM35.

\subsection{Perancangan Perangkat Keras Perancangan} perangkat keras merupakan penjelasan tentang masing masing perangkat keras yang digunakan pada penelitian ini. Masing masing dijelaskan dengan sederhana dengan menggunakan simbol simbol yang sesuai dengan komponen yang (Hardware)

Setelah dilakukan perancangan terhadap masing masing perangkar keras, maka tahap selanjutnya adalah tahap perancangan untuk keseluruan perangkat keras (hardware). TTTPerangkat keras seperti Arduino ESP6288, LCD (Liquid Crystal Display), I2C (Inter Intergrated Circuit), sensor suhu LM35, dan Buzzer. Yang dihubungkan menjadi satu dengan arduino melalui port port yang telah ditentukan . pada tahap ini, keseluruan unit perangkat keras atau rangkaian alat diwujudkan menjadi sebuah prototype sehingga dapat disimulasikan secara langsung.

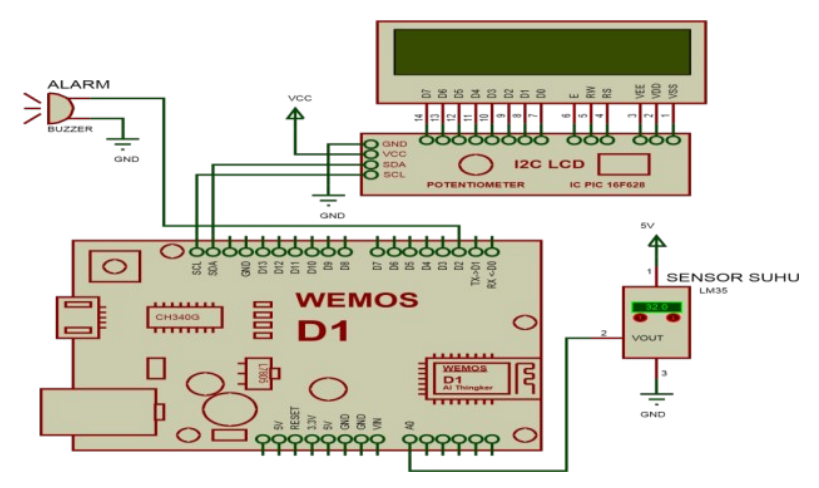

Gambar 7. Rangkaian seluruh perangkat

Gambar diatas adalah rangkaian keseluruhan alat yang telah kita buat penjelasannya adalah sebagai berikut :

1. Arduino ESP8266 merupakan kontrol utama.

2. Pin SDA SCL Arduino dihubungkan ke $I 2 C$ LCD pada pin VCC, GND, SD, SCL.

3. I2C LCD terhubung dengan LCD $16 \times 2$. Pin D0 sampai dengan D7 sebagai komukasi data, sedangkan $E, R W, R S$ sebagai pin pengendali LCD.

4. Alaram menggunkan Buzzer $5 v$ yang terhubung pada pin D2 Arduino ESP8266.

5. Sensor Suhu Menggunkan LM35 yang terhubung pada pin Analog A0.

\subsection{Implementasi Sistem}

Implementasi sistem adalah seuah tahapan untuk menerapkan aplikasi yang telah dibuat sebelumnya, agar tercipta sebuah aplikasi yang diinginkan.

Tahapan langkah-langkah implementasi, yaitu:

1. Menyediakan Hardware dan Software. Pada tahap ini, kebutuhan yang diperlukan penulis 
untuk membangun sebuah aplikasi yaitu dari segi hardware dan software.

2. Membangun Sistem.

Di tahap ini adalah tahapan dimana penulis membangun sebuah sistem yang sudah dirancang.

3. Menjalankan sistem alat yang telah dibuat. Tahap ini merupakan menjalakan sistem yang telah dibangun/dibuat dan mengecek ulang hasil akhir dari sistem alat apakah berjalan sesuai dengan seperti apa yang diinginkan.

\subsection{Cara Kerja Alat}

Sebelum masuk pada tahap imlementasi dan pengujian alat, penulis akan menjelaskan terlebih dahulu cara kerja alat ini, yaitu sebagai berikut :

a. Pengambilan Data Suhu dari Internet Of Think (IOT).

Untuk mendapatkan data suhu dari internet of thing (iot) pada rangkaian alat ini kita harus mengkoneksikan internet terlebih dahulu pada alat ini, setelah itu kita dapat mengambil data suhu dari internet dengan mengakses website internet of thingk,

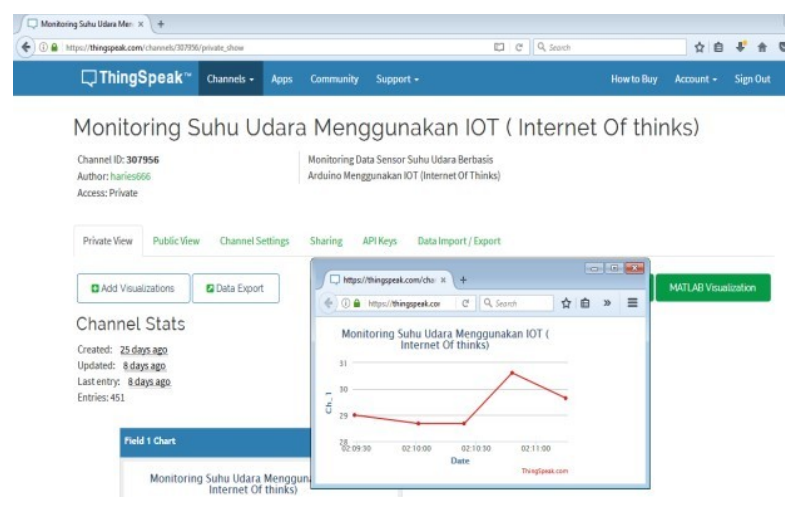

Gambar 8. Monitoring suhu udara

\subsection{Perangkat Lunak (Software)}

Perangkat lunak yang digunakan untuk membuat alat Monitoring Suhu Udara ini adalah :

1. Windows 7 32-bit.

2. Internet Of Think (IOT).

3. Aplikasi Arduino IDE.

4. Proteus 8 Profesional.

5. Basic4android.

\subsection{Perangkat Keras (Hardware}

Perangkat keras yang digunakan untuk pembuatan Monitoring Suhu Udara ini adalah 1. Laptop Hp Intel Inside 2. Memorry 2GB.

3. Harddisk 500GB.

Dan beberapa perangkat keras yang akan ditunjukkan di gambar dibawah.

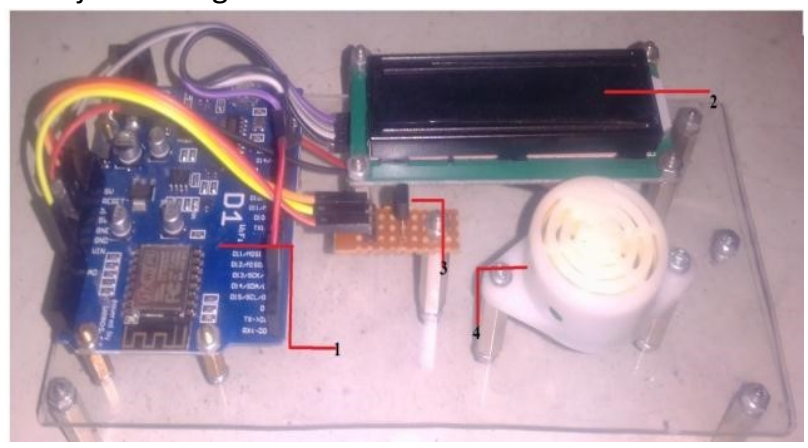

Gambar 9

\subsection{Pengujian Alat}

Pengujian sistem alat bertujuan untuk menguji coba dan mengetahui apakah alat bekerja sesuai dengan spesifikasi perencanaan yang telah direncanakan sebelumnya. Pengujian ini dilakukan untuk mengetahui kerja perangkat keras pada masing masing rangkaian dapat bekerja dengan baik antara lain pengujian arduino dengan Icd, pengujian rangkaian arduino dengan sensor Im35, pengujian rangkaian arduino pada buzzer. Data hasil pengujian yang diperoleh nantinya akan di bahas untuk di jadikan dalam pengambilan kesimpulan.

\subsection{Pengujian Arduino dengan LCD}

Pengujian ini dilakukan untuk mengetahui apakah arduino sudah berjalan dengan baik atau belum sesuai dengan yang direncanakan. Langkahlangkah yang dilakukan :

1. Klik start Windows $\rightarrow$ All Program Arduino.exe.

2. Pada softwarearduino, klik File New.

3. Kemudian muncul kotak dialog seperti gambar dibawah. 


\section{Gambar 10}

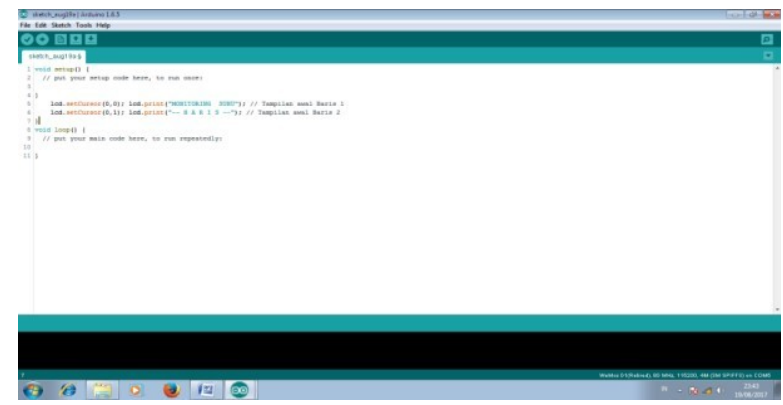

Gambar 11

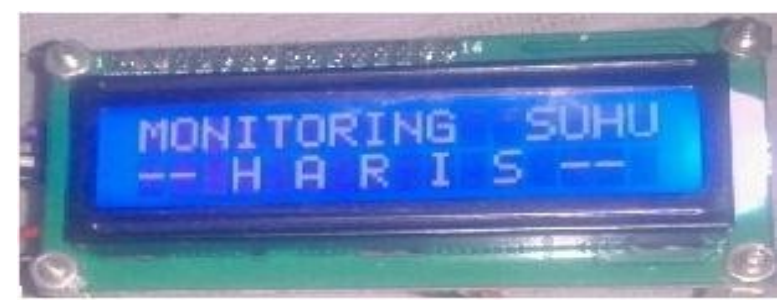

Gambar 12

Program untuk pengujian arduino dengan LCD untuk menampilkan teks seperti pada gambar diatas. Pada program Icd setCursor $(0,0)$; menunjukkan bahwa karakter pertama dari - MONITORING SUHU\| terletak pada sumbu cursor $\mathrm{x}=0$ dan $\mathrm{y}=0$, maksudnya pada kolom pada kolom pertama dan baris pertama. Kemudian pada program Icd.setCursor $(0,1)$; yaitumenunjukkan bahwa cursor $\mathrm{x}=0$ dan $\mathrm{y}=1$ yaitu - - HARIS- - Dimulai dari kolom pertama pada baris kedua.

\subsection{Pengujian Arduino dengan Sensor Suhu LM35 dan Buzzer}

Pengujian rangkaian sensor LM35 ini dilakukanuntuk mengetahui kelebihan dan kekurangan sensor suhu ini dalam mendeteksi suhu udara, seta apakah rangkaian sensor sudah bekerja dengan baik atau tidak. Pengujian rangkaian sensor suhu dilakukan dengan memasang sensor LM35 di rangkaian pada tempat tinggi sebagai sumber sensor. Sama hal dengan pengujian arduino dengan LCD, pada pengujian yang dilakukan pada sensor suhu LM35, yaitu juga dengan menggunakan program arduino IDE dengan suhu yang telah di tentukan. Pengukuran sensor suhu LM35 dilakukan untuk mengetahui suhu pada suatu tempat dan nilai suhu yang naik akan di tampilkan pada server

Program Studi Teknik Informatika Universitas Prima Indonesia (UNPRI) Medan
Internet Of Thing (IOT) yang diikuti dengan buzzzer sebagai penanda suara, maka rangkaian sensor dinyatakan berhasil atau bagus.

Langkah langkah yang dilakukan untuk mengupload program ke Arduino :

1. Klik start Windows All Program Arduino.exe.

2. Pada software arduino, klik File New.

3. Kemudian muncul kotak dialog dan ketikkan program.

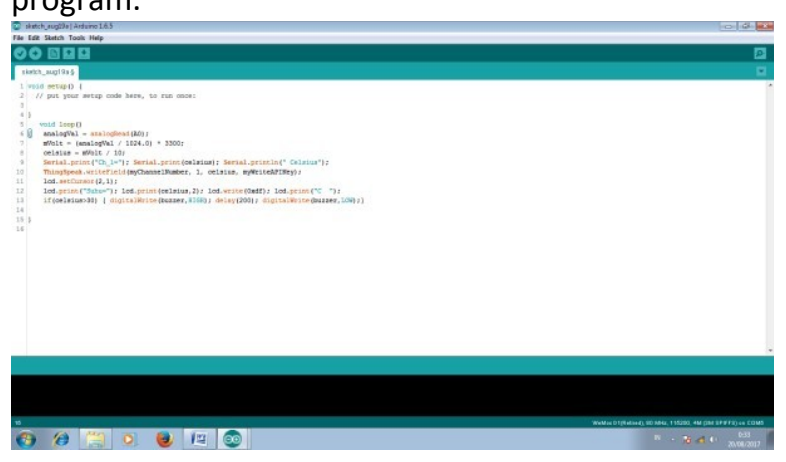

Gambar 13

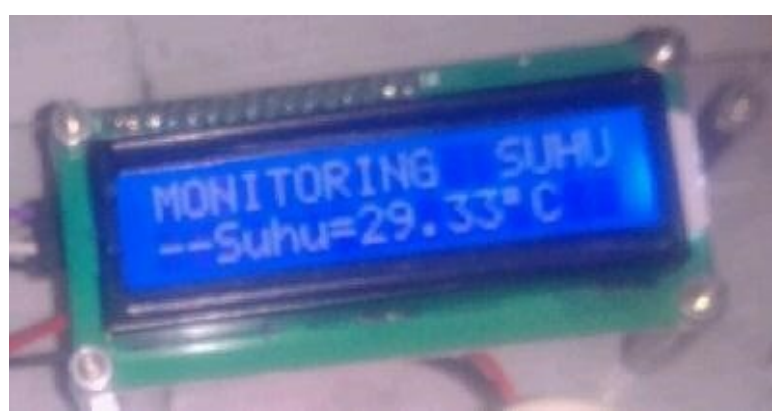

Gambar 14

Setelah program di upload ke rangkaian alat, alat ini secara otomatis berjalan sesuai program, pada gambar 4.9 adalah tampilan nilai sensor suhu LM35, nilai tampilan sensor suhu LM35 akan muncul di LCD pada setiap kurang lebih 50 detik dan di ikuti dengan suara buzzer.

\subsection{Pengujian Arduino dengan IOT (Internet Of Things)}

Pengujian ini dilakukan untuk mengethui apakah sistem monitoring suhu udara menggunakan Internet of Thing sudah berjalan dengan baik atau belum sesuai dengan yang di rencanakan. Untuk mengetahui apakah ini berjalan dengan baik maka harus menjalakan program arduino IDE dan mengunakan aplikasi Internet Of Think (IOT) terlebih dahulu untuk 
merancang sebuah aplikasi yang nantinnya bisa dia jalankan di aplikasi Internet Of Think (IOT) agar Memonitoring Suhu Udara dapat di ketahui dengan mudah.

Langkah langkah yanag di lakukan untuk mengupload program :

1. Klik start Windows All Program Arduino.exe.

2. Pada software arduino, klik File New.

3. Kemudian muncul kotak dialog dan ketikkan program.

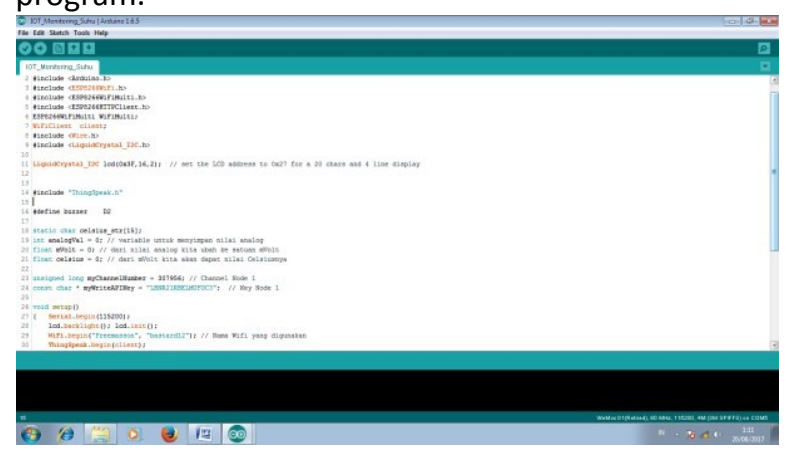

Gambar 15

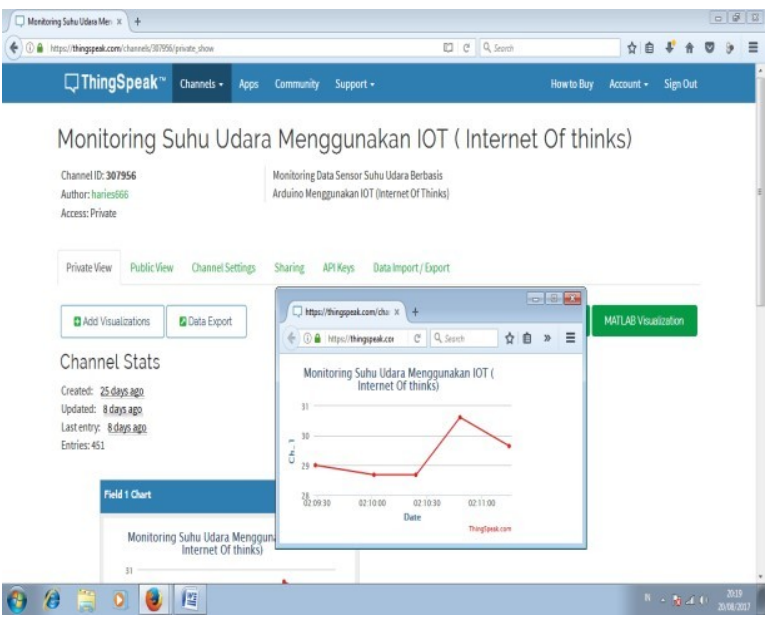

Gambar 16

Setelah itu maka langkah selanjutnya adalah menjalankan program tersebut. Brikut adalah langkah langkah menjalankan pengujian menampilkan suhu udara pada Software Internet Of Think.

a. Login sebagai admin pada Software IOT .

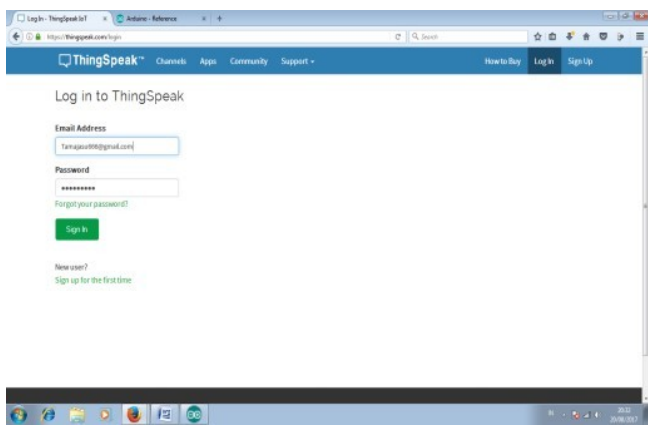

Gambar 17

b. Setelah berhasil login akan masuk ke form monitoring Suhu Udara yang ditunjuk pada gambar dibawah.

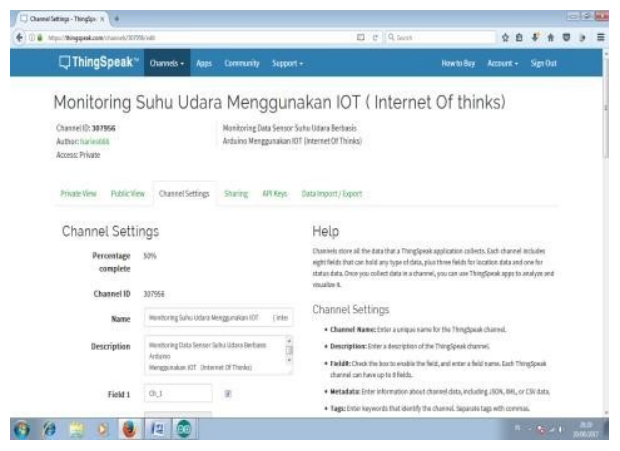

Gambar 18

\section{KESIMPULAN DAN SARAN}

\subsection{Kesimpulan}

Setelah selesai meakukan tahap perancangan dan pembuatan sistem yang kemudian dilanjutkan dengan tahap implementasi dan pengujian alat maka dapar diambil kesimpulan bahwa sutuk merancang dan membangu sebuah alat yang mampu membantu manusia dalam mengetahui suhu udara yang berada disuatu tempat atau di ketinggian yang sulit terjangkau oleh manusia.

1. Alat dapat bekerja sebagai pe-monitor suhu udara pada tempat yang berbeda dengan mengirimkan datanya melalui internet.

2. Sensor Im35 merupakan sensor yang efektif untuk mendeteksi suhu.

3. Sensor suhu LM35 mengalami perubahan pada outputnya 10 miliVolt setiap derajat celcius $(10 \mathrm{mV} / \mathrm{C})$.

4. Arduino tidak dapat membaca nilai suhu secara langsung, karena itu digunakan ADC untuk menterjemahkan nilai analog yang dikeluarkan

Program Studi Teknik Informatika 
sensor menjadi data digital yang sudah kompatibel dan dapat dibaca oleh Arduino.

5. Arduino merupakan pusat pengolah data yang cukup handal dalam mengukur dan mengontrol suhu.

\subsection{Saran}

Adapun saran yang dapat penulis sampaikan adalah sebagai berikut :

1. Sebaiknya sensor diletakkan di tempat yang jauh dari PC agar bisa memonitoring suhu udara yang berbeda.

2. Sebaiknya untuk memonitoring suhu udara harus terkoneksi jaringan internet agar memonitoring suhu udara dapat berjalan dengan baik.

3. Dalam pengembangan selanjutnya penulis berharap sistem monitoring suhu udara ini dapat dikembangkan dengan teknologi-teknologi yang lebih moderen seperti dapat di koneksikan dengan Smartphone/Android.

\section{5. DAFTAR PUSTAKA}

[1] Andrianto, Heri dan Aan Darmawan. 2015. Arduino Belajar cepat Pemograman. Bandung. Iformatika Bandung.

[2] Arduino.2016. Tersedia Online http://kelas-mikrokontroller. Diakses Mei 2016.

[3] Juwita Safitri, Meqorry Yusfi, Astuti. 2014. Rancang Bangun Alat Ukur Resistivitas Lapisan Tipis Mmenggunakan Metode 4 Probe Berbasis ATMega8535 Dengan Tampilan LCD Karakter 2x16. Jurnal Fisika Unand.

[4] Latupeirissa Dolpfy, A.Suoth Verna, S.Kolibu Hesky. 2015. Rancang Bangun Alat Ukur Suhu dan Kadar Alkohol Menggunakan Sensor LM35 dan Sensor MQ-3. Jurnal Ilmiah Sains.

[5] Lubis, Abdul Jabar. 2016. Panduan Praktis Arduino Untuk Pemula. Medan. E-Book.

[6] Nur, M. 2012. Alat Pengukur Suhu Otomatis Berbasis Mikrokontroleler ATMega8535 dengan Penampil LCD. Skripsi. Medan: Fakultas Matematika dan
Ilmu Pengetahuan Alam Universitas Sumatra Utara.

[7] Riyadi Slamet, Purnama Bambang Eka. 2013. Sistem Pengendalian Keamanan Pintu Rumah Berbasis SMS (Short Massage Service) Menggunakan Mikrokontroller ATMega8535. Jurnal IJNS Indonesia Journal on Networking and Security.

[8] Suherman, IrwinAndriyanto, Dwiyanto Saleh, 2015. Rancangan Alat Ukur Temprature Server Menggunakan Sensor LM35 Berbasis SMS Getway. Jurnal PROSISKO 2015.

[9] Syam, Rafiuddin. 2013. Dasar Dasar Teknik Sensor. Fakultas Teknik Universitas Hasanuddin. Makkasar.

[10] Syahbudin, S.Kom. 2016. Analisis Penerapan Smart City dan Internet of Things (IOT) di INDONESIA. Jurnal Syahbudin, S.Kom.

[11] Yefri Hendrizon, Widan. 2012. Rancang Bangun Alat Ukur Tingkat Kekeruhan Zat Cair Berbasis AT89S51 Menggunakan Fototransistor dan Penampilan LCD. Jurnal Fisika Unand. 